\title{
Open reduction and internal fixation in a case with transscaphoid perilunate dislocation 8 months after the injury: a patient with a 5-year follow-up
}

\author{
Bashir Ahmed Mir - Shabir Ahmed Dhar • \\ Mohammed Ramzan Mir - Mohammed Farooq Butt • \\ Asif Sultan · Tahir Ahmed Dar · Mohammed Iqbal Wani
}

Received: 30 November 2007/ Accepted: 7 May 2008/Published online: 13 June 2008

(C) Springer-Verlag 2008

\begin{abstract}
The management of perilunate dislocations diagnosed later than three months continue to elicit debate with literature being scarce. We report a 22-year-old male with transscaphoid perilunate dislocation who reported to our hospital 8 months after sustaining the injury. Open reduction was done along with bone grafting. Five years after the surgery the patient is symptom-free with an excellent range of motion.
\end{abstract}

Keywords Transscaphoid perilunate $\cdot$ Non union · Dislocation

\section{Introduction}

Perilunate injuries range from mild to severe injuries of the carpi, all of which pose a challenge to the treating orthopaedician. One of the problems associated with this injury is the difficulty of its accurate and early recognition. This is so because the injury can occur in multiple variants which may require additional radiographs for diagnosis [1].

Late presentation combined with missed diagnosis often causes critical delay in the treatment of these injuries. This often results in progressive traumatic arthritis with pain and dysfunction [2]. The literature regarding missed injuries is scarce with Gellman stating that the outcome of delayed treatment of such injuries is unpredictable. [3].

We report a 22-year-old male with transscaphoid perilunate dislocation who reported to our hospital 8 months

B. A. Mir · S. A. Dhar $(\bowtie) \cdot$ M. R. Mir .

M. F. Butt - A. Sultan - T. A. Dar - M. I. Wani

Government Hospital for Bone and Joint Surgery, Barzullah,

Srinagar 190005, Kashmir, India

e-mail: shabirdhar@yahoo.co.in after sustaining the injury. Open reduction was done along with bone grafting. Five years after the surgery the patient is symptom-free with an excellent range of motion.

\section{Case report}

A 22-year-old male painter reported to our hospital with a history of pain in the Median nerve distribution of the left hand. The patient's symptoms dated back a month. He, however, admitted to having fallen from a height while painting a window 8 months earlier. The wrist had been bandaged for a fortnight after the trauma after which the patient had resumed his work with mild discomfort persisting in the wrist. On examination, the patient was found to have no motor or sensory deficit in the median nerve distribution.

Palpation revealed tenderness over the space of Poirer. The wrist range of motion was globally restricted. The patient was advised radiographs in the anteroposterior, Oblique and lateral planes. Study of these radiographs showed that the patient had a transscaphoid perilunate dislocation of the carpi with the ulnar component being the fracture of the ulnar styloid (Fig. 1). The patient was informed about his pathology and advised to undergo surgery. The patient was operated upon using a combined dorsal and volar approach. The condition of the cartilage of the lunate and the scaphoid was surprisingly found to be good. The lunate was reduced after clearing its bed and the proximal scaphoid pole was provisionally fixed to the lunate with a $\mathrm{k}$ wire. The scaphoid fracture was cleared and a graft interposed between the two fragments to restore the height of the bone and to prevent hump-back deformity. The reduction was held with a $\mathrm{k}$ wire inserted from the distal pole (Fig. 2). The capsule was repaired meticulously before 
Fig. 1 Anteroposterior, oblique and lateral radiographs depicting the transscaphoid perilunate dislocation. The ulnar styloid is fractured instead of the common lunatotriquetral dissociation
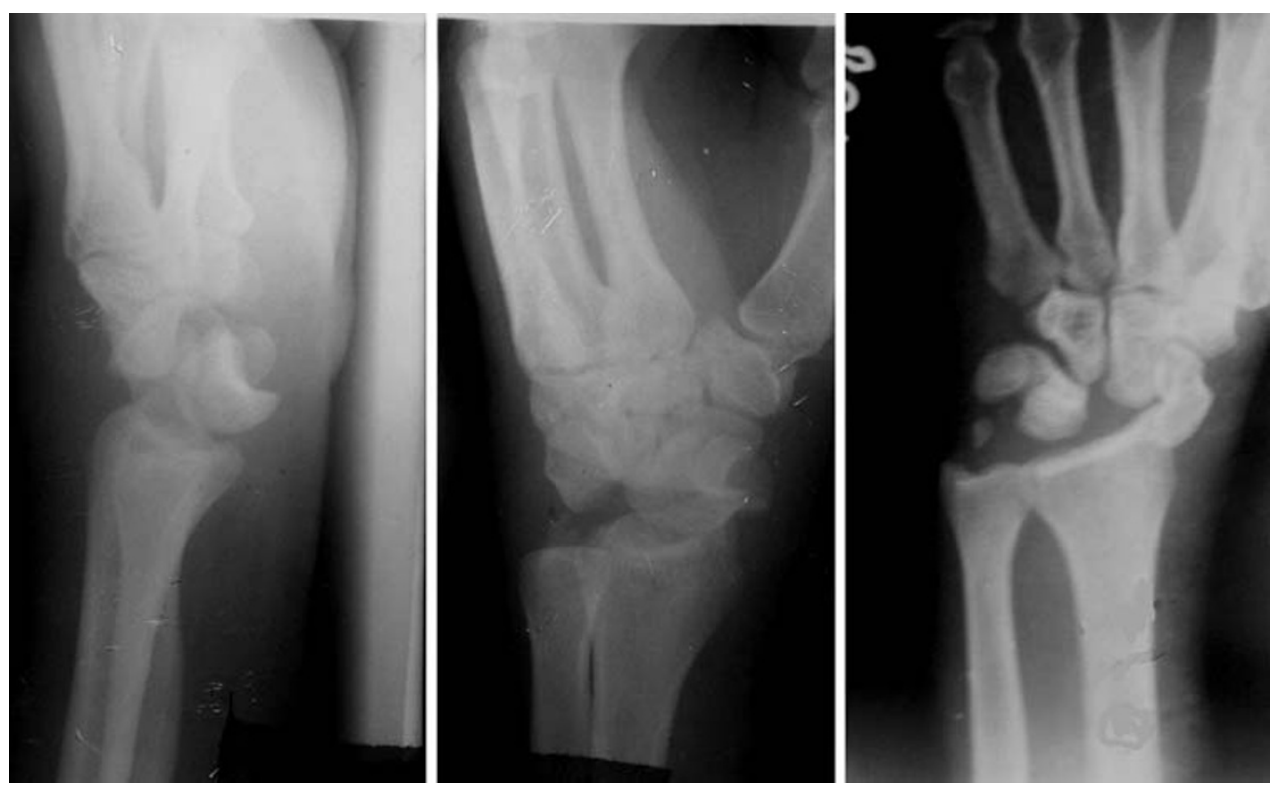

Fig. 2 Radiographs taken after open reduction, bone grafting of the scaphoid and internal fixation
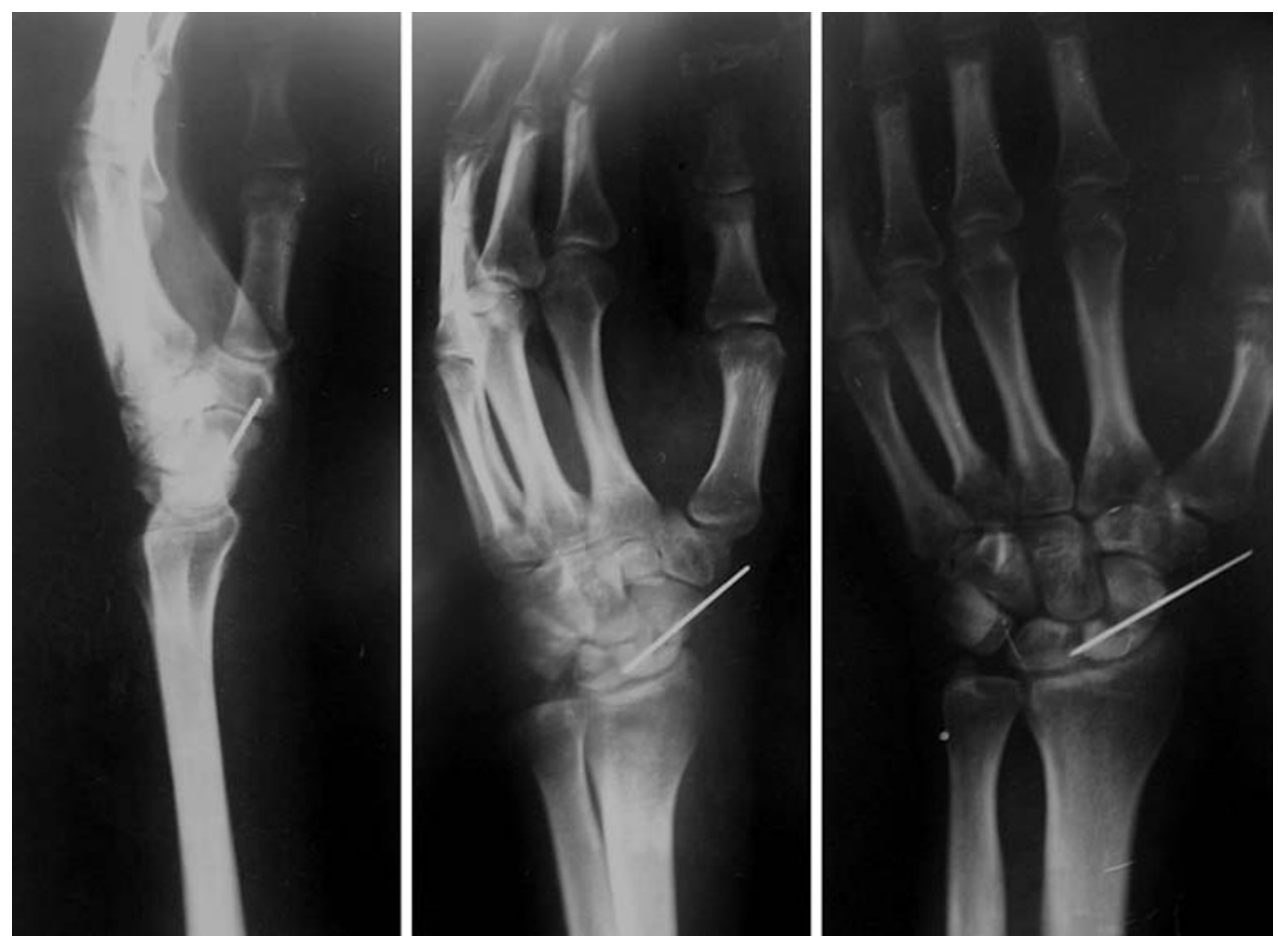

closure of the skin. Postoperatively the wrist was immobilized in a sugar tong splint. Finger exercises were encouraged. Stitches were removed at 2 weeks and a plaster of Paris cast applied. At 4 weeks the $\mathrm{k}$ wire was removed under local anesthesia. The plaster cast was continued for 8 weeks when union was visible on radiographs. The patient was started on a range of motion exercises.

The patient was progressing satisfactorily at 6 months when he was lost to follow-up. Five years after the surgery the patient returned to the hospital with a complaint of low-back pain. His wrist was radiographed after obtaining consent. Both the clinical and radiographic examinations revealed no abnormality. The active range of motion of the wrist was $135^{\circ}$ in the flexion extension arc (flexion $0^{\circ}-70^{\circ}$, extension $0^{\circ}-65^{\circ}$ ) $65^{\circ}$ in radioulnar deviation $\left(0^{\circ}-36^{\circ}\right.$ radial deviation and $0^{\circ}-29^{\circ}$ ulnar deviation) and $110^{\circ}$ of pronation supination $\left(0^{\circ}-55^{\circ}\right.$ pronation and $0^{\circ}-55^{\circ}$ supination). The passive range of motion as measured by the examiner was the same. The grip strength of the patient was $29 \mathrm{~kg}$ compared to the $32 \mathrm{~kg}$ on the opposite side as measured on the dynamometer (Fig. 3). 
Fig. 3 Anteroposterior, oblique and lateral radiographs taken 5 years after surgery. The ulnar styloid shows asymptomatic non union
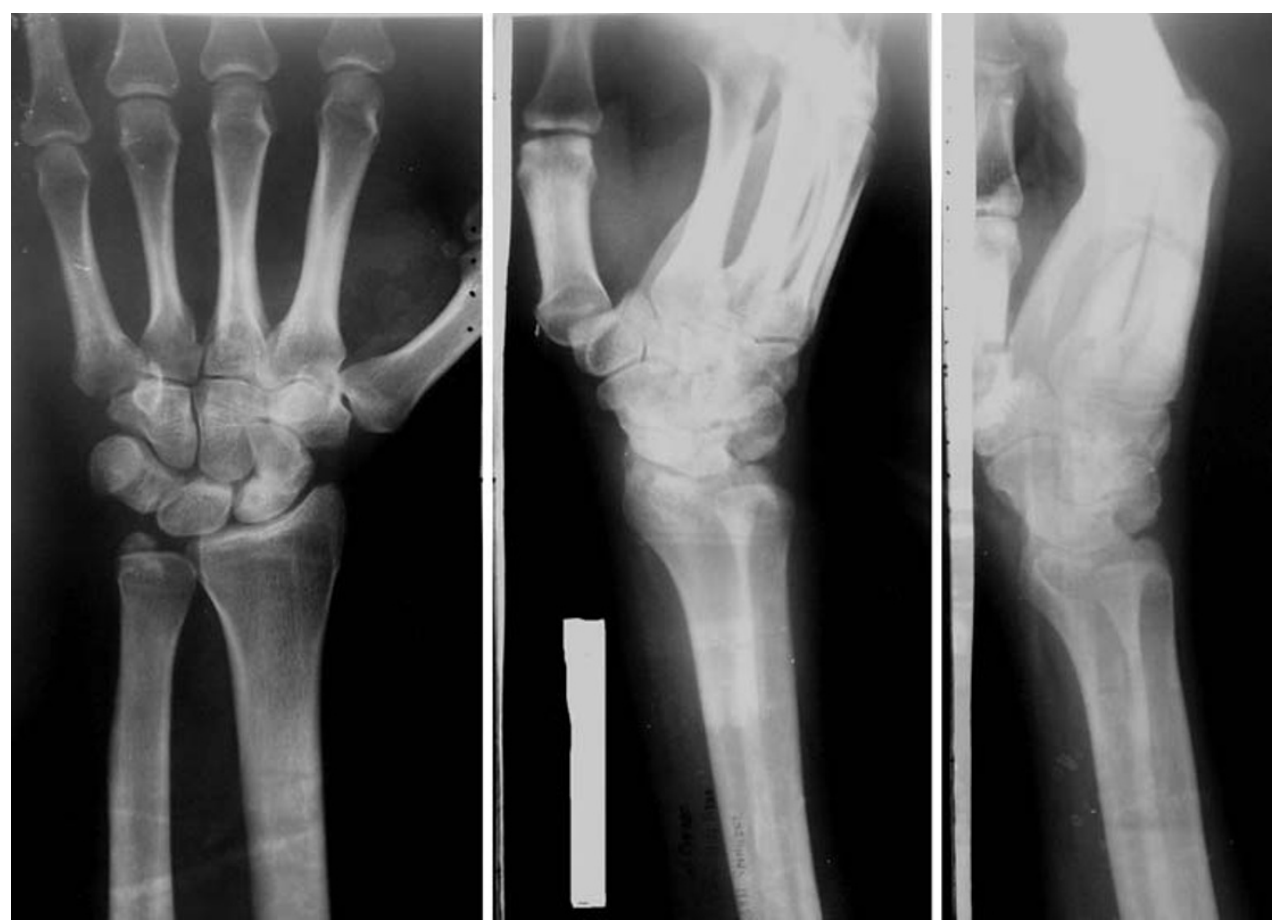

\section{Discussion}

The transscaphoid perilunate dislocation is an uncommon injury sustained due to force transmission through a hyperextended wrist [4]. Mayfield classified lunate dislocation as the most severe form of perilunar instability [5]. According to the line of force transmission and disruption these injuries are classified as lesser arc injuries when the injury passes through radial styloid, midcarpal joint and lunatotriquetral space. Greater arc injuries pass through the scaphoid, capitate and the triquetrum. Lesser and greater arc injuries can be considered as three stages of perilunate fracture and ligament instabilities [6].

Chronic injuries are classified as those injuries that are more than 3 months old. Seigert [7] felt that injuries upto 3 months old are potentially treatable by open reduction and internal fixation.

According to Pandit various patterns of transscaphoid fracture dislocations have been described; yet, there is little information on the method of management and long-term results of such severe and rare injuries [8]. Reinforcing the problems of delayed management $\mathrm{Su}$ et al. [4] found that prompt open reduction following acute injuries gave more promising results. According to Herzberg [2] the initial appraisal of these injuries has a direct impact on the outcome.

Krasin et al. [9] reviewing the neglected nonunion of the scaphoid felt that radiographic and symptomatic osteoarthritis of the wrist are inevitable causing lifelong morbidity and disability.
Delay in the diagnosis in such injuries is always a possibility due to inadequacy of the routine radiographs and the bizarre appearance of the disrupted carpal bones. In our part of the world patients with such injuries often report late.

Literature regarding the management of such injuries in case of delayed presentation is rare [7]. Wrist arthrodesis and proximal row carpectomy are relatively mutilating surgeries that leave a significant functional deficit. Dislocation in this region requires rapid realignment, as untreated perilunate dislocation or dislocation of the lunate bone will lead to serious secondary damage, which can only be treated by salvage operations involving loss of function [10]. Acute post-traumatic PRC can be indicated, but is rarely reported in literature and cannot be used as a first line procedure [11].

Our patient who presented 8 months after the injury and had a follow-up of 5 years with an excellent functional outcome, which possibly points out the fact that open reduction and internal fixation should be the first line treatment for such injuries diagnosed after a delay of more than 3 months.

\section{References}

1. Kozin SH (1998) Perilunate injuries; diagnosis and treatment. JAAOS 6:114-120

2. Herzberg G, Comtet JJ, Linschied RL et al (1993) Perilunate dislocations and fracture dislocations. A multicenter study. J Hand Surg [Am] 18:768-779 
3. Gellman H, Schwartz SD, Botte MJ, Feiwell L (1988) Late treatment of a dorsal transscaphoid, transtriquetral perilunate wrist dislocation with avascular changes of the lunate. Clin Orthop Relat Res Dec(237):196-203

4. Su CJ, Chang MC, Liu Y, Lo WH (1996) Lunate and perilunate dislocation. Zhonghua Yi Xue Za Zhi (Taipei) 58(5):348-354

5. Mayfield JK, Johnson RP, Kilcoyne RK (1980) Carpal dislocations; pathomechanics and progressive perilunar instability. J Hand Surg [Am] 5:226-241

6. Johnson RP (1980) The acutely injured wrist and its residuals. Clin Orthop 149:33-44

7. Seigert JJ, Frassica FJ, Amadio PC (1988) Treatment of chronic perilunate dislocations. J Hand Surg 13A:206-212
8. Pandit R (1998) Proximal and palmar dislocation of the lunate and proximal scaphoid as a unit in a case of scaphocapitate syndrome. A 32-month follow-up. J Hand Surg [Br] 23(2):266268

9. Krasin E, Goldwirth M, Gold A, Goodwin DR (2001) Review of the current methods in the diagnosis and treatment of scaphoid fractures. Postgrad Med J 77:235-237

10. Voight $C$ (2006) Injury to the heel of the hand. Unfallchirurg 109(4):313-22 (quiz 323-4)

11. van Kooten EO, Coster E, Segers MJ, Ritt MJ (2005) Early proximal row carpectomy after severe carpal trauma. Injury 36(10):1226-1232 (epub 29 March 2005) 